\title{
Astrochemistry as a Gateway to Teaching and Learning Threshold Concepts in Physical Chemistry
}

\author{
Wilson K. Gichuhi* \\ Department of Chemistry, Tennessee Tech University, 1 William L. Jones Dr., Cookeville, TN 38505 \\ *Corresponding author: wgichuhi@tntech.edu
}

Received June 17, 2019; Revised June 27, 2019; Accepted July 08, 2019

\begin{abstract}
The purpose of this paper is to examine the use of astrochemistry examples in teaching the potential threshold concepts (TCs) of physical chemistry that are contained in the recently published Physical Chemistry Anchoring Concepts Content Map (PChem-ACCM). The paper provides a brief overview of how selected astrochemical examples can be utilized to teach and learn suggested TCs that are commonly encountered in the three main overarching areas of physical chemistry curriculum, namely: chemical kinetics, quantum chemistry, and thermodynamics. Using astrochemical examples to decipher the abstract nature of the many fundamental physical chemistry concepts, which are usually accompanied by rigorous mathematical treatments, provides a rich ground in which to implement alternative teaching pedagogies and practices that can help the learner master the associated TCs.
\end{abstract}

Keywords: Astrochemistry, physical chemistry, kinetics, quantum chemistry, thermodynamics, curriculum

Cite This Article: Wilson K. Gichuhi, "Astrochemistry as a Gateway to Teaching and Learning Threshold Concepts in Physical Chemistry." World Journal of Chemical Education, vol. 7, no. 3 (2019): $209-215$. doi: 10.12691/wjce-7-3-4.

\section{Introduction}

Since its inception, the idea of threshold concepts (TCs) $[1,2,3]$ has continued to receive considerable interest across several disciplines, with a majority of studies focusing on their identification [4-11]. Nevertheless, research on the implementation of teaching pedagogies and techniques aimed at facilitating enhanced learning and mastery of TCs has not received much attention. A scrutiny of TC theory research reveals that the topic is still in its infancy within the chemical education research field, especially with regard to subjects such as physical chemistry that may be viewed to have "too many threshold concepts to count"'[7]. In this article, we identify potential TCs that fall within the 10 anchoring concepts of the recently published PChem-ACCM [12] and illustrate how astrochemistry can be used to promote deeper and more transformative learning necessary for overcoming barriers associated with the mastery and teaching of these TCs. According to Meyer and Land [1], TCs are troublesome, bounded, irreversible, and integrative concepts that, once grasped, allow new and previously inaccessible ways of perceiving and thinking about a subject. Mastery of TCs involves discarding the usual ways of seeing and thinking about a subject matter, which makes understanding the concepts difficult, and acquiring new, productive ways of thinking. To this end, this position paper offers suggestions on how astrochemistry examples can be integrated into a traditional physical chemistry curriculum to enable the learner to discard the negative and low expectations that result from viewing physical chemistry as a mathematically dominated and difficult course. It is well-documented that students come to physical chemistry courses with negative perceptions and low expectations [13]; hence, the use of exciting, real-world examples in explaining fundamental physical concepts can go a long way in assisting the learner in crossing the associated learning barriers.

In terms of research, the field of astrochemistry [14,15] has successfully continued to grow, providing a rich set of educational materials that chemistry educators can utilize in the classroom to stimulate the learning of TCs. Such materials include visual images; the hitherto large number of atoms, molecules, and ions discovered in the world of the interstellar medium (ISM); planetary and ISM chemical reactions and schemes; and the spectra of atoms and molecules that exist in the interstellar space $[16,17,18]$.

\section{Astrochemistry Research and Chemical Education: The Missing Link}

During the 2012 American Chemical Society (ACS) National Meeting in Philadelphia, the ACS Physical Chemistry division established a new Astrochemistry subdivision for scientists who are interested in integrating astrochemical aspects of chemistry in their research through experiments, theory, observation, and modelling. One of the main objectives of the division is to promote the astrochemistry discipline into undergraduate students in chemistry, physics, and astronomy by encouraging students to pursue graduate studies in the field. To 
encourage such endeavors, the Astrochemistry subdivision has established active student-centered programs such as the competitive ACS Astrochemistry Dissertation Award. However, it is worthwhile to note that although the astrochemistry-based research has continued to flourish with many cutting-edge research findings, the topic has not gained much prominence in the chemistry curriculum, with only a few institutions offering an undergraduate astrochemistry curriculum in the United States, for example. However, there exists quite a number of astrochemistry-related chemical education research papers, with varying discussion topics and suggested classroomrelated exercises and projects [19-25].

\section{Astrochemistry and Threshold Concepts in Physical Chemistry}

Astrochemists examine chemical compositions and processes of stars, planets, comets, and interstellar media $[14,15,26]$. They look at how atoms, molecules, ions, and free radicals interact outside of Earth's atmosphere, contributing to our understanding of geological and chemical processes of other planets. It is, therefore, not surprising that chemistry shares numerous concepts with astrochemistry, especially with regard to physical chemistry, that are essential for students to master.

From classroom experience, most physical chemistry instructors have admitted their awareness of the presence of too many concepts that students fail to master $[27,28,29]$. Some of the major barriers to achieving this mastery is the disconnect between the many abstract topics in physical chemistry and the real world, lack of instructor pedagogical content knowledge (PCK), and unclear connection between student mathematical ability and success in physical chemistry [30]. These barriers suggest the existence of numerous TCs that the physical chemistry student and the instructor have not been able to identify and deal with succinctly during their educational journey. In the past, physical chemistry education has received some critique due to its unusually high reliance on mathematical techniques, with a recommendation for less focus on mathematical derivations and more attention to knowledge and skills useful in producing chemists and engineers more qualified for graduate studies and employment in the industrial sector [29,31]. In their provocative opinion, Moore and Schwenz [32] suggested that physical chemistry instructors deviate from utilizing mathematical abstractions upon which the foundations of chemistry are laid. Instead, Moore and Schwenz propose that material be presented in a manner that excites students by illustrating the usefulness of the content while still ensuring proper understanding of the mathematical principles involved. While the suggestions proposed by Moore and Schwenz [32] and other physical chemistry educators $[33,34,35]$ are to some extent valid, the implementation of this approach relies on the successful use of exciting and student-centered illustrations necessary for grasping TCs in physical chemistry, without neglecting the critical aspect played by mathematics in the development of fundamental concepts. Based on this dilemma, this article offers suggestions on how potential TCs in physical chemistry can be tackled using astrochemistry-related examples to motivate and elicit curiosity in mathematically rich topics of thermodynamics, quantum chemistry and molecular spectroscopy. If adopted in the classroom, such examples may transform the learner's view of abstract concepts for better conceptual understanding. The availability of these numerous astrochemistry examples that exemplify core fundamental physical chemistry principles can open portals to new and previously inaccessible ways of thinking (by learners) and teaching (by educators) if integrated in the traditional physical chemistry curriculum. The few astrochemistry examples provided in this article can also be used as a strong foundation in developing new teaching practices and curriculum to improve student understanding of physical chemistry as recommended in the recent nationwide Survey on Undergraduate Physical Chemistry course [36].

\section{Threshold Concepts in Chemistry: What is Known so Far?}

In the last 10 years, several educators have identified a number of TCs in chemistry such as acid strength [37], atomicity [11,38], chemical bonding [6], chemical equilibrium [6] and intermolecular forces [6]. Talanquer [6] describes how students employ implicit (i.e., tacit, unconscious) schemas in their thinking, suggesting that they must shift their schema first before they can grasp TCs such as intermolecular forces and chemical equilibrium. Some of the TCs in organic chemistry as revealed by Duis [39] are: reaction mechanisms; acid-base chemistry; synthesis; stereochemistry; resonance (electron delocalization); molecular orbital theory; spectroscopy; polarity; SN1, SN2, E1, and E2 reactions; and curved-arrow formalism. In terms of high school education, Park et al. identified seven threshold concepts in Korea that include mole, ideal gas law and periodic table, structure of an atom, electron configuration, orbital, chemical bond, and chemical equilibrium [40]. The lack of TC-related education research in physical chemistry calls for serious consideration of this topic by physical chemistry educators. As part of the physical chemistry curriculum reform, the identification of TCs will go a long way in incorporating new teaching pedagogies into the traditional course structure that can help students cross the associated thresholds and be successful.

\section{Threshold Concept Identification in Physical Chemistry: The Challenge}

After TCs are identified, the next stage lies in creating a strong physical chemistry foundation and curriculum by streamlining the volume and content of what is taught, why it is taught, how it is taught, and when it is taught. This will, in turn, provide a rich and valuable, studentfocused classroom experience that is conducive to the learner's mastery of the TCs. This goal has been featured in several physical chemistry education research projects $[35,41]$. As noted in a number of reports, identifying the $\mathrm{TC}$ in a discipline is not trivial since the TC itself can be a 
threshold concept for both the teacher and the learner $[42,43]$. A major challenge in identifying TCs in a discipline, therefore, becomes understanding what a $\mathrm{TC}$ is, what makes it a TC and for whom [2]. As such, in most cases, the suitability of a concept being identified as a threshold one becomes questionable if identified by teachers and educators who may have already transversed the perceived threshold. To this end, the question of who should be involved in the initial identification of TCs is critical if a long-term impact on curriculum design and development is to be realized. It is not surprising that a majority of past studies on the identification of TCs in different disciplines have oftentimes involved the teacher's/lecturer's viewpoint first before incorporating students' alternative or secondary perspectives. A recent study on active learning in physical chemistry in the USA has revealed a continued prevalence of instructor-centered approaches to teaching physical chemistry [44], resonating very well with the aforementioned teacher-dominated approaches in TC identification. This kind of instructor-centered approach in the initial identification of TCs is expected since, as learners, students may not have the knowledge and skills necessary to identify TCs in the field. The recently published PChem-ACCM [12] provides a summary of 10 anchoring concepts that lay a rich ground for initial identification of TCs in a typical physical chemistry curriculum. The finergrained, core concepts from the PChem-ACCM [12] listed in Table 1 are used in this paper as a starting ground for the identification of TCs in an undergraduate physical chemistry curriculum. Column 3 in Table 1 provides a brief description of astrochemistry examples that may be utilized in teaching the potential TCs.

Table 1. Summary of physical chemistry anchoring concepts, and selected potential threshold concepts with examples of how astrochemistry may be utilized to teach the concepts

\begin{tabular}{|c|c|c|}
\hline Anchoring Concept & $\begin{array}{l}\text { Suggested Threshold } \\
\text { Concept(s) }\end{array}$ & Astrochemistry Examples \\
\hline $\begin{array}{l}\text { 1) Atoms: Chemical and physical } \\
\text { characteristics of matter are } \\
\text { determined by the internal } \\
\text { structure. }\end{array}$ & $\begin{array}{l}\text { Atomic structure/spectra of } \\
\text { the hydrogenic atom } \\
\text { Molecular structure } \\
\text { Hyperfine structure } \\
\text { Nuclear spin }\end{array}$ & $\begin{array}{l}\text { Stellar absorption spectra: The absorption of specific wavelengths of light proves } \\
\text { the presence of hydrogen gas in the outer atmosphere of a star. } \\
\text { The largest group of the interstellar species is diatomic molecules and radicals. } \\
\text { First-detection diatomic interstellar molecules like } \mathrm{CH}, \mathrm{CN} \text {, and } \mathrm{CH}^{+} \text {provide } \\
\text { quantum treatment of rotation, vibration and electronic movements. [45,46] } \\
\text { The discovery of the } \mathrm{HI} 21 \mathrm{~cm} \text { line in low-density regions of the ISM }[47,48] \mathrm{OH} \\
18 \mathrm{~cm} \text { transition as a thermometer for molecular clouds [49]. } \\
\text { Ortho-para ratio measurements of species such as } \mathrm{H}_{3}^{+}, \mathrm{CH}_{2}, \mathrm{C}_{3} \mathrm{H}_{2} \text {, and } \mathrm{H}_{2} \mathrm{O} \text {. The } \\
\text { behavior of } \mathrm{H}_{2}\left(\mathrm{~J}=1 \text { in comparison to } \mathrm{H}_{2}(\mathrm{~J}=0) \text { during collisions involving }\right. \\
\text { molecules such as } \mathrm{NH}_{3} \text { exemplifies nuclear-spin effects that control the } \\
\text { abundance of ortho- } \mathrm{H}_{2}[50] \text {. }\end{array}$ \\
\hline $\begin{array}{l}\text { 2) Chemical Bonding: Interaction } \\
\text { of atoms through electrostatic } \\
\text { forces to form chemical bonds. }\end{array}$ & $\begin{array}{l}\text { Transition dipole moment } \\
\text { Molecular orbital theory }\end{array}$ & $\begin{array}{l}\text { The use of carbon monoxide (CO) in mapping out molecular regions through its } \\
\text { detection with radio waves is due to CO's strong electric dipole moment. } \\
\text { The molecular orbital diagram of } \mathrm{H}_{3}^{+} \text {, which is the simplest polyatomic molecule } \\
\text { and the most abundantly produced interstellar molecule, after } \mathrm{H}_{2} \text {. }\end{array}$ \\
\hline $\begin{array}{l}\text { 3) Structure/Function: The } \\
\text { existence of geometric structures } \\
\text { that dictate chemical and physical } \\
\text { behaviors of compounds. }\end{array}$ & $\begin{array}{l}\text { Electronic, vibrational and } \\
\text { rotational motions } \\
\text { Role of group theory in } \\
\text { symmetry and selection } \\
\text { rules in spectroscopy }\end{array}$ & $\begin{array}{l}\text { Interaction of molecules with radiation through transitions between their } \\
\text { electronic, vibrational, and rotational states is the basis of numerous detections of } \\
\text { interstellar molecules, ions and radicals. } \\
\text { The inversion transition of } \mathrm{NH}_{3}(\lambda \sim 1.2 \mathrm{~cm}) \text { as a special case where the } \\
\text { molecular structure helps in spectroscopic detection. (The lowest rotational } \\
\text { transition is at } \lambda \sim 0.5 \mathrm{~mm} \text {.) }\end{array}$ \\
\hline $\begin{array}{l}\text { 4) Inter-molecular Interactions: } \\
\text { Both the intermolecular and } \\
\text { electrostatic forces between } \\
\text { molecules play a role in } \\
\text { determining matter's physical } \\
\text { behavior. }\end{array}$ & $\begin{array}{l}\text { Transition dipole moment } \\
\text { Polarity } \\
\text { Van der Waals radius }\end{array}$ & $\begin{array}{l}\text { Since } \mathrm{H}_{3}{ }^{+} \text {is an equilateral triangle, there is no permanent dipole moment and } \\
\text { hence no ordinary rotational spectrum. } \\
\text { Non-polar species like } \mathrm{C}_{2}, \mathrm{C}_{3}, \mathrm{C}_{4} \text {, and } \mathrm{C}_{5} \text { have been detected through their IR and } \\
\text { FIR bands in circumstellar envelopes while anions such as } \mathrm{C}_{8} \mathrm{H}^{-}, \mathrm{C}_{4} \mathrm{H}^{-}, \mathrm{CN}^{-}, \mathrm{C}_{3} \mathrm{~N} \\
\text {, and } \mathrm{C}_{5} \mathrm{~N}^{-} \text {have also been detected in the mm spectrum of IRC+10216. [51]. } \\
\text { Detection of } \mathrm{H}_{2} \text { dimer in Jupiter: In the ISM, temperatures are generally very low } \\
(<300 \mathrm{~K}) \text {; hence, rotational excitation of a molecule colliding with He or } \mathrm{H}_{2} \\
\text { usually involves systems in their electronic ground state such as the van der } \\
\text { Waals complex [52]. }\end{array}$ \\
\hline $\begin{array}{l}\text { 5) Chemical Reactions: Chemical } \\
\text { reactions lead to the formation of } \\
\text { chemical products that have new } \\
\text { chemical and physical properties. }\end{array}$ & $\begin{array}{l}\text { Activation energy } \\
\text { Potential energy diagrams }\end{array}$ & $\begin{array}{l}\text { Collisions leading to chemical reactions are those that have enough energy to } \\
\text { break bonds. Free radicals and ions lead to efficient ion-molecule reactions that } \\
\text { proceed without activation energy at temperatures as low as } 10 \mathrm{~K} \text { (Langevin } \\
\text { expression). } \\
\text { The dominance of ion-neutral reactions in the ISM that are orders of magnitude } \\
\text { faster than neutral-neutral reactions. }\end{array}$ \\
\hline $\begin{array}{l}\text { 6) Energy and Thermo-dynamics: } \\
\text { The key currency in molecular and } \\
\text { macroscopic systems is energy. }\end{array}$ & Entropy & $\begin{array}{l}\text { Thermal } \mathrm{H} / \mathrm{D} \text { exchange in polar ice where deuteron scrambling affords favorable } \\
\text { entropy for the reaction: } \mathrm{H}_{2} \mathrm{O}+\mathrm{D}_{2} \mathrm{O} \rightleftharpoons 2 \mathrm{HDO} \text { with respect to the backward } \\
\text { reaction [53]. }\end{array}$ \\
\hline $\begin{array}{l}\text { 7) Chemical Kinetics: Chemical } \\
\text { changes have a time scale over } \\
\text { which they occur. }\end{array}$ & $\begin{array}{l}\text { Reaction rates } \\
\text { Molecularity and reaction } \\
\text { mechanisms } \\
\text { Transition state theory }\end{array}$ & $\begin{array}{l}\text { Due to low density and temperature in the ISM, conditions of thermodynamic } \\
\text { equilibrium are uncommon. It is only in planetary (or stellar) atmospheres that } \\
\text { thermal equilibrium is achieved. } \\
\text { Three-body collisions are absent or extremely unlikely in space. Reactions such } \\
\text { as } \mathrm{A}+\mathrm{B} \rightarrow \mathrm{AB} \text { may only occur significantly with radiative stabilization, or on } \\
\text { the surface of a grain. } \\
\text { Interstellar surface-catalyzed formation of water: the reaction } \mathrm{H}^{+} \mathrm{H}_{2} \mathrm{O}_{2}^{-} \rightarrow \mathrm{H}_{2} \mathrm{O}+ \\
\mathrm{OH}[54] \text {. }\end{array}$ \\
\hline
\end{tabular}




\begin{tabular}{|c|c|c|}
\hline Anchoring Concept & $\begin{array}{l}\text { Suggested Threshold } \\
\text { Concept(s) }\end{array}$ & Astrochemistry Examples \\
\hline $\begin{array}{l}\text { 8) Chemical Equilibrium: In } \\
\text { principle, all chemical changes are } \\
\text { reversible, often reaching a state of } \\
\text { dynamic equilibrium. }\end{array}$ & $\begin{array}{l}\text { Gibbs energy and chemical } \\
\text { equilibrium } \\
\text { Free energy and } \\
\text { equilibrium }\end{array}$ & $\begin{array}{l}\text { Chemistry in diffuse and translucent clouds. } \\
\text { UV photons and cosmic rays can penetrate the clouds to ionize atoms and } \\
\text { dissociate molecules, leading to short timescales for achieving equilibrium (few } \\
\text { thousand years). }\end{array}$ \\
\hline $\begin{array}{l}\text { 9) Experiments, Measurement and } \\
\text { Data: Chemistry is generally } \\
\text { advanced via empirical } \\
\text { observation. }\end{array}$ & $\begin{array}{l}\text { Spectroscopic frequencies } \\
\text { and intensities } \\
\text { Gas-phase reactions } \\
\text { Vibrational and rotational } \\
\text { populations }\end{array}$ & $\begin{array}{l}\text { Chemical processes occurring in space can be simulated in the laboratory at low } T \\
\text { (as low as } 10 \mathrm{~K} \text { ) and low pressure. } \\
\text { Temperature and irradiation by UV light or energetic particles of ice samples can } \\
\text { be controlled in the lab. Astrophysical laboratories: Leiden, Catania, NASA } \\
\text { Ames/Goddard. } \\
\text { Molecules in solid state cannot rotate, just vibrate - Spectra solid and gas phase } \\
\text { molecules look very different: Pure rotational lines occur mostly in the far-IR/sub } \\
\text { mm. } \\
\text { The use of radio telescopes in the discovery of the "signature" line of hydrogen at } \\
21 \mathrm{~cm}(1420 \mathrm{MHz} \text { ) wavelength between stars. } \\
\text { Cross-beam experiments and cavity ring down spectroscopy experiments as } \\
\text { applied to many astrochemistry measurements. }\end{array}$ \\
\hline $\begin{array}{l}\text { 10) Visualization: Chemistry } \\
\text { constructs meaning interchangeably } \\
\text { at the particulate and macroscopic } \\
\text { levels. }\end{array}$ & $\begin{array}{l}\text { Potential energy diagrams } \\
\text { and tunneling }\end{array}$ & $\begin{array}{l}\text { Reaction between the hydroxyl radical }(\mathrm{OH}) \text { and methanol }\left(\mathrm{CH}_{3} \mathrm{OH}\right) \text {, one of the } \\
\text { most abundant organic molecules in space, is almost two orders of magnitude } \\
\text { larger at } 63 \mathrm{~K} \text { than previously measured at } \sim 200 \mathrm{~K}[55,56] \text {. }\end{array}$ \\
\hline
\end{tabular}

\section{Selected Astrochemistry Examples in Teaching Potential Threshold Concepts}

\subsection{Activation Energy, Quantum Tunneling, and Potential Energy Surfaces}

With its molecular complexity, the interstellar medium (ISM) can, from a physical concept point of view, be seen as a gas-phase volume where basic principles of gas phase kinetics can be inferred [16]. Of particular interest is the presence of low ISM temperatures that are sometimes accompanied by fast chemical kinetics that allows spectroscopic observation of unstable isomers such as the simplest enol, vinyl alcohol [57,58]. The continued discovery of unusual molecules in the ISM is indicative of a natural availability of efficient chemical conditions and processes that are superior to the commonly encountered laboratory environments. One example of such a process is the solid-state catalytic effect of dust grains [59]. The surface of these dust grains acts as a catalyst to activate numerous interstellar chemical kinetics that could otherwise be hindered by low temperature conditions, providing a rich example explaining the concept of activation energy, catalysis and quantum mechanical tunneling $[17,60]$. These chemical kinetics examples can be used to enhance student understanding of complex concepts in chemical kinetics, providing an alternative conceptual change in the chemical kinetics instructional approach [61]. For advanced kinetics classes, the observation of unstable vinyl alcohol under low temperature conditions prevalent in cold, dark nebulae can be utilized to teach the concepts of quantum tunneling and low temperature kinetics in chemical dynamics and kinetics classes.

Generally, most physical chemistry students are familiar with the standard Arrhenius equation and the concept of activated reactions. However, the discussion of quantum mechanical tunneling introduces a concept that becomes difficult to grasp. The use of astrochemical examples, such as the rapid reaction between the hydroxyl radical $(\mathrm{OH})$ and methanol $\left(\mathrm{CH}_{3} \mathrm{OH}\right)$ at interstellar temperatures as facilitated by tunneling, may assist students in changing their view about dramatic reactivity enhancements at low temperatures, which is a deviation from the traditional view of activated reactions. Exposing students to chemical reactions that are a consequence of odd quantum mechanical rules may provide alternative ways of thinking about quantum mechanics since the students will start seeing real applications of the abstract quantum mechanical principles that are usually accompanied by rigorous mathematical treatments involving the wavefunction. Furthermore, to the physical instructors, the use of such an astrochemical example with the associated potential energy surface may present a real-world example of a case where a harmonic oscillator can tunnel into classically forbidden regions, enhancing the concept of calculating tunneling probability for a harmonic oscillator that is usually mentioned in introductory quantum mechanics.

Although the concept of activation energy [62] is one of the earliest concepts a physical chemistry student learns, it can be mysterious and difficult to visualize especially where very low temperatures are involved (close to zero K). Part of this difficulty may be because students are used to the fact that every reaction needs some kind of activation energy to occur; hence, at very low temperatures, molecules may not even have any kinetic energy to be involved in any collisions. The activation energy concept then gets tied up to potential energy surfaces (PES), with questions about which reactions are likely to take place at low temperatures, and the driving force behind such reactions. It is at this point that the use of the many ion-molecule reactions relevant to astrochemistry (Table 1) and their associated PES becomes critical in assisting students in obtaining a clear understanding of the concept of activation energy, PES and quantum mechanical tunneling.

\subsection{Atomic and Molecular Spectra}

According to a recent Survey on Physical Chemistry course, at least $90 \%$ of physical chemistry instructors reported some degree of course coverage in subtopics on the history of quantum mechanics, postulates of quantum mechanics, and molecular spectroscopy [36]. Of particular interest is the more than $92 \%$ combined moderate and 
great coverage on the history of quantum mechanics by the interviewed faculty [36]. This presents an excellent opportunity for utilizing astrochemistry-related examples during the very first few lectures of quantum chemistry to invoke curiosity and dispel negative perceptions that usually hinder students from understanding various TCs that fall under various overarching anchoring concepts in physical chemistry such as atoms, bonding, structure and function. Bruce offers a similar approach to utilizing the first day of physical chemistry class to shape students' initial impression about the subject [33]. To maintain the first-day excitement, Bruce suggests the introduction of macroscopic, molecular-level, and mathematical models to describe physical and chemical processes as a strategy to excite and motivate students to remain successful throughout the course [33]. As mentioned by Hudson, the development of astrochemistry largely parallels the development of quantum spectroscopy, with the latter being the best known tool for exploring and understanding the diverse molecules that exist in the ISM, together with their associated spectra [24]. As a result, instead of introducing the "emergence of quantum theory" using the historical examples in many classical physical chemistry textbooks, one can use the ultraviolet and visible wavelength astrochemistry with a brief history of the rotational or vibrational spectra of selected astrochemistry-relevant molecules. Some authors have suggested designing course curricula around particular themes, such as the history of the discipline, as a teaching strategy to ease the difficulties involved in teaching challenging subjects [31]. Using rotational astrochemistry signatures from radio to far-infrared frequencies in the initial interstellar molecular detection of interstellar molecules, such as $\mathrm{CH}[63,64]$ and $\mathrm{CN}[64,65]$, is an excellent way to raise students' interest, thus easing the difficulties involved in explaining the potential fundamental threshold concepts in spectroscopy. The use of such astrochemistry-related, non-traditional textbook atomic and molecular spectra examples may indeed assist in transforming the learner's view of the suggested threshold concepts as listed in Table 1. The introduction of other astrochemistry examples such as the discovery and importance of the $\mathrm{H} 21 \mathrm{~cm}$ line in low-density regions of the ISM [47,48], the $\mathrm{OH} 18 \mathrm{~cm}$ transition as a thermometer for molecular clouds [49], and the ortho-para measurements of species such as $\mathrm{H}_{3}{ }^{+}, \mathrm{CH}_{2}$, and $\mathrm{C}_{3} \mathrm{H}_{2}$ may assist in teaching concepts involving nuclear spin and hyperfine splitting.

\subsection{Transition Dipole Moment, Selection Rules, and Hyperfine Structure}

Almost all quantum chemistry lectures and textbooks begin the discussion of quantum theory by outlining how classical mechanics fails in describing microscopic systems [34,66]. This historical discussion then moves swiftly to mathematical treatments of spectroscopic transitions, with the introduction of the transition dipole moment (TDM) integral [67]. The TDM integral defines the wavefunction interaction in a spectroscopic transition, leading to a set of selection rules that governs spectral transitions under the influence of light. The interpretation of atomic and molecular spectra lies on the understanding of spectroscopic section rules. In a traditional physical chemistry curriculum, the transition dipole moment is an obvious starting point for deriving selection rules that govern electronic, vibrational and rotational transitions. As mentioned by Ellis [68], selection rules and the transition dipole moment are two concepts that many students find somewhat obscure and troublesome in that students do not understand how they relate to underlying physical principles. We include the concept of selection rules and the transition dipole as potential TCs and list astrochemistry examples that can be used in teaching these TCs (refer to Table 1). These astrochemistry examples can potentially be transformative in that students can see a strong justification for where these concepts are indeed applicable.

A clear understanding of selection rules, as well as a strong justification for their physical existence in the interpretation of several astrochemistry-related atomic and molecular spectra, lays a strong foundation for subsequent quantum mechanical derivations based on the TDM integral. To reduce discouragement and encourage live participation by the students on this topic, one may introduce the subject using examples listed in Table 1 where low pressure, density and temperatures make the ISM a natural laboratory for isolated, single molecule gas-phase chemistry where spectroscopic selection rules govern the type of molecular spectra observed. For example, the presence of interstellar clouds at temperatures as low as $10-100 \mathrm{~K}$ makes the ISM a perfect laboratory for observing photon emission in the radio part of the electromagnetic spectrum, following a decay of the excited rotational states [26,69]. Numerous molecular systems ranging from simple diatomic and polyatomic molecules such as carbon monoxide $(\mathrm{CO})$, water $\left(\mathrm{H}_{2} \mathrm{O}\right)$, and ammonia $\left(\mathrm{NH}_{3}\right)$ to more complex biological precursor molecules have been detected using this strategy [70,71]. However, even though the simplest homonuclear diatomic molecule, $\mathrm{H}_{2}$, is very abundant in the ISM, it cannot be detected using this strategy due to the lack of permanent electrical dipole moments that make transitions between pure rotational levels forbidden [72]. These astrochemistry examples can be utilized by physical chemistry instructors to introduce the concept of selection rules and dipole moment concepts in molecular spectroscopy.

\section{Conclusion}

Several academic disciplines have continued to explore the idea of TCs as powerful tools for opening new doors to explore successful teaching practices and pedagogic design. This will deepen students' mastery and understanding concepts that are traditionally considered conceptually difficult. However, while there has been pioneering chemical education research focusing on the identification of TCs in general and organic chemistry, the topic has not gained much prominence in physical chemistry, despite it being one of the most challenging courses in chemistry from both students' and lecturers' points of view. The central goal of this paper has been to highlight how astrochemistry-based examples can be successfully utilized in teaching and learning the potential TCs in physical chemistry that fall within the framework 
of the PChem-ACCM. Although only a few examples are discussed in this article, astrochemistry is rich in exciting modern teaching and learning aids that could potentially open new and transformative ways of thinking by students to help them navigate through the curriculum. Utilization of these examples will go a long way in helping teachers to move beyond the historical structure of physical chemistry courses to achieve a formidable evolution in physical chemistry education.

\section{Funding}

This study was funded by a Tennessee Tech Faculty Startup grant.

\section{Disclosure Statement}

The authors declare no competing financial interests.

\section{References}

[1] J.H.F. Meyer, R. Land, Threshold concepts and troublesome knowledge (2): Epistemological considerations and a conceptual framework for teaching and learning, High. Ed. 49 (2005) 373-388.

[2] R. Land, J. H. F. Meyer, M. T. Flanagan, Threshold Concepts in Practice, Sense Publishers, Rotterdam/Boston/Taipei, 2016.

[3] J. Meyer, R. Land, Threshold Concepts and Troublesome Knowledge, ESRC Teaching and Learning Research Programme Project No L139251099, 2006.

[4] J. Loertscher, S. Lin, V. Minderhout, D. Green, J.E. Lewis, Identification of threshold concepts for biochemistry, CBE Life Sci. Educ. 13 (2014) 516-528.

[5] K.R. Davey, Results from a study with Threshold Concepts in two chemical engineering undergraduate courses, Educ. Chem. Eng. 7 (2012) e139-e152.

[6] V. Talanquer, Threshold Concepts in Chemistry: The Critical Role of Implicit Schemas, J.Chem.Ed. 92 (2015) 3-9.

[7] R. Serbanescu, Identifying Threshold Concepts in Physics: too many to count!, Practice and Evidence of Scholarship of Teaching and Learning in Higher Education 12 (2017) 19.

[8] S.A. Male, D. Bennett, Threshold concepts in undergraduate engineering: Exploring engineering roles and value of learning, Aust. J. Engin. Ed. 20 (2015) 59-69.

[9] K. Davey, Results from a study with Threshold Concepts in two chemical engineering undergraduate courses, Educ. Chem. Eng. 7 (2012) e139-e152.

[10] S. Psycharis, Inquiry Based-Computational Experiment, Acquisition of Threshold Concepts and Argumentation in Science and Mathematics Education, J. Educ. Sci. Technol. 19 (2016) 282-293.

[11] N. Didiş, L. Wang, Students' mental models of atomic spectra, Chem. Educ. Res. Pract. 17 (2016) 743--755|.

[12] T.A. Holme, J.J. Reed, J.R. Raker, K.L. Murphy, The ACS Exams Institute Undergraduate Chemistry Anchoring Concepts Content Map IV: Physical Chemistry, J.Chem.Ed. 95 (2018) 238-241.

[13] M. Sözbilir, What Makes Physical Chemistry Difficult? Perceptions of Turkish Chemistry Undergraduates and Lecturers, J.Chem.Ed. 81 (2004) 573.

[14] E. Herbst, J.T. Yates, Introduction: Astrochemistry, Chem. Rev. 113 (2013) 8707-8709.

[15] V. Barone, M. Biczysko, C. Puzzarini, Quantum Chemistry Meets Spectroscopy for Astrochemistry: Increasing Complexity toward Prebiotic Molecules, Acc. Chem. Res. 48 (2015) 1413-1422.

[16] E. Herbst, The Chemistry of Interstellar Space, Angew. Chem. 29 (1990) 595-608.

[17] E. Herbst, The synthesis of large interstellar molecules, Int. Rev. Phys. Chem. 36 (2017) 287-331.

[18] E. Herbst, E.F. van Dishoeck, Complex Organic Interstellar Molecules, Annu. Rev. Astron. Astrophys. 47 (2009) 427-480.
[19] N. Glickstein, Before There Was Chemistry: The Origin of the Elements as an Introduction to Chemistry, J. Chem. Educ. 76 (1999) 353.

[20] O. Sorkhabi, W.M. Jackson, I. Daizadeh, Cometary Spectroscopy for Advanced Undergraduates, J. Chem. Educ. 75 (1998) 1472.

[21] V.E. Viola, Formation of the chemical elements and the evolution of our universe, J. Chem. Educ. 67 (1990) 723.

[22] J.S. Huebner, R.A. Vergenz, T.L. Smith, Astronomy Matters for Chemistry Teachers, J. Chem. Educ. 73 (1996) 1073.

[23] R. Pagni, Astrochemistry-From Astronomy to Astrobiology (Andrew M. Shaw), J.Chem.Ed. 84 (2007) 233.

[24] R.L. Hudson, Astrochemistry Examples in the Classroom, J.Chem.Ed. 83 (2006) 1611

[25] L.N. Anumukonda, A. Young, D.G. Lynn, R. Buckley, A. Warrayat, C.L. Graves, H.D. Bean, N.V. Hud, Adenine Synthesis in a Model Prebiotic Reaction: Connecting Origin of Life Chemistry with Biology, J. Chem. Educ. 88 (2011) 1698-1701.

[26] M. De Becker, Astrochemistry: the issue of molecular complexity in astrophysical environments, Bull. Soc. R. Sci. Liege 82 (2013) 33-94, $62 \mathrm{pp}$.

[27] L. Mammino, Teaching Physical Chemistry in Disadvantaged Contexts: Challenges, Strategies and Responses, in: M. GuptaBhowon, S. Jhaumeer-Laulloo, H. Li Kam Wah, P. Ramasami (Eds.), Chemistry Education in the ICT Age, Springer Netherlands, Dordrecht, 2009, pp. 197-223.

[28] K.E. Hahn, W.F. Polik, Factors Influencing Success in Physical Chemistry, J.Chem.Ed. 81 (2004) 567.

[29] M.R. Mack, M.H. Towns, Faculty beliefs about the purposes for teaching undergraduate physical chemistry courses, Chem. Educ. Res. Pract. 17 (2016) 80-99.

[30] K. Padilla, J. Van Driel, The relationships between PCK components: the case of quantum chemistry professors, Chem. Educ. Res. Pract. 12 (2011) 367-378.

[31] I.M. Greca, O. Freire, Teaching introductory quantum physics and chemistry: caveats from the history of science and science teaching to the training of modern chemists, Chem. Educ. Res. Pract. 15 (2014) 286-296.

[32] R.J. Moore, R.W. Schwenz, The problem with P. Chem, J.Chem.Ed. 69 (1992) 1001.

[33] C.D. Bruce, Beyond the Syllabus: Using the First Day of Class in Physical Chemistry as an Introduction to the Development of Macroscopic, Molecular-Level, and Mathematical Models, J.Chem.Ed. 90 (2013) 1180-1185.

[34] G.G. Hoffman, Using an Advanced Computational Laboratory Experiment To Extend and Deepen Physical Chemistry Students' Understanding of Atomic Structure, J.Chem.Ed. 92 (2015) 10761080.

[35] G. Tsaparlis, Teaching and Learning Physical Chemistry: A Review of Educational Research, Advances in Teaching Physical Chemistry, American Chemical Society2007, pp. 75-112.

[36] L.J. Fox, G.H. Roehrig, Nationwide Survey of the Undergraduate Physical Chemistry Course, J.Chem.Ed. 92 (2015) 1456-1465.

[37] H. Tümay, Emergence, Learning Difficulties, and Misconceptions in Chemistry Undergraduate Students' Conceptualizations of Acid Strength, Sci. Educ. 25 (2016) 21-46.

[38] E.J. Park, G. Light, Identifying Atomic Structure as a Threshold Concept: Student mental models and troublesomeness, Int. J. Sci. Educ. 31 (2009) 233-258.

[39] J.M. Duis, Organic Chemistry Educators' Perspectives on Fundamental Concepts and Misconceptions: An Exploratory Study, J.Chem.Ed. 88 (2011) 346-350.

[40] E.J. Park, Analysis and identification of students' threshold concepts in high school chemistry, J. Korean Chem. Soc. 58 (2014) 126-137.

[41] G.R. Van Hecke, What to Teach in Physical Chemistry: Is There a Single Answer?, Advances in Teaching Physical Chemistry, American Chemical Society2007, pp. 11-27.

[42] S. Barradell, The identification of threshold concepts: a review of theoretical complexities and methodological challenges, High. Ed. 65 (2013) 265-276.

[43] J.H.F. Meyer, Helping our students : learning, metalearning, and threshold concepts, in: J.C. Hughes, J. Mighty (Eds.), Taking stock : research on teaching and learning in higher education., School of Policy Studies, Queen's University, McGill-Queen's University Press, Montreal, 2010, pp. 191-213. 
[44] J. Donnelly, F.E. Hernandez, Fusing a reversed and informal learning scheme and space: student perceptions of active learning in physical chemistry, Chem. Educ. Res. Pract. 19 (2018) 520-532.

[45] B.S. Ryden, A.A. Stark, Molecules in galaxies. I. Carbon monoxide observations in a spiral arm of M31, Astrophys. J. 305 (1986) 823-829.

[46] A.A. Stark, B.G. Elmegreen, D. Chance, Molecules in galaxies. V. Carbon monoxide observations of flocculent and grand-design spirals, Astrophys. J. 322 (1987) 64-73.

[47] C.B. Moore, C.L. Carilli, K.M. Menten, Neutral hydrogen $21 \mathrm{~cm}$ absorption at red shift 2.6365 toward the gravitational lens $\mathrm{MG}$ J0414+0534, Astrophys. J. 510 (1999) L87-L90.

[48] W.T. Reach, C. Heiles, B.C. Koo, The nature of unidentified farinfrared point sources, Astrophys. J. 412 (1993) 127-145.

[49] E. Yuji, I. Hiroshi, S. Nami, M.M. Karl, M. Hiroyuki, Y. Satoshi, $\mathrm{OH} 18 \mathrm{~cm}$ Transition as a Thermometer for Molecular Clouds, Astrophys. J. 815 (2015) 13.

[50] K.N. Crabtree, N. Indriolo, H. Kreckel, B.J. McCall, The ortho:para ratio of $\mathrm{H}_{3}{ }^{+}$in laboratory and astrophysical plasmas, AIP Conference Proceedings 1642 (2015) 380-383.

[51] J. Cernicharo, M. Guelin, C. Kahane, A $\lambda 2 \mathrm{~mm}$ molecular line survey of the C-star envelope IRC+10216, Astron. Astrophys., Suppl. Ser. 142 (2000) 181-215.

[52] S.J. Kim, L.M. Trafton, T.R. Geballe, Z. Slanina, 2- $\mu$ m absorption features of hydrogen dimers in the equatorial spectra of Jupiter, Icarus 113 (1995) 217-219.

[53] T. Lamberts, S. Ioppolo, H.M. Cuppen, G. Fedoseev, H. Linnartz, Thermal H/D exchange in polar ice - deuteron scrambling in space, Monthly Notices of the Royal Astronomical Society 448 (2015) 3820-3828.

[54] T. Lamberts, P.K. Samanta, A. Koehn, J. Kaestner, Quantum tunneling during interstellar surface-catalyzed formation of water: the reaction $\mathrm{H}+\mathrm{H}_{2} \mathrm{O}_{2} \rightarrow \mathrm{H}_{2} \mathrm{O}+\mathrm{OH}$, Phys. Chem. Chem. Phys. 18 (2016) 33021-33030.

[55] M. Antinolo, M. Agundez, E. Jimenez, B. Ballesteros, A. Canosa, G. El Dib, J. Albaladejo, J. Cernicharo, Reactivity of $\mathrm{OH}$ and $\mathrm{CH}_{3} \mathrm{OH}$ between 22 and $64 \mathrm{~K}$ : modeling the gas phase production of $\mathrm{CH}_{3} \mathrm{O}$ in Barnard 1b, Astrophys. J. 823 (2016) 25/21-25/28.

[56] O. Roncero, A. Zanchet, A. Aguado, Low temperature reaction dynamics for $\mathrm{CH}_{3} \mathrm{OH}+\mathrm{OH}$ collisions on a new full dimensional potential energy surface, Phys. Chem. Chem. Phys. 20 (2018) 25951-25958.
[57] S. Saito, Microwave spectroscopic detection of vinyl alcohol, CH2:CHOH, Chem. Phys. Lett. 42 (1976) 399-402.

[58] B.E. Turner, A.J. Apponi, Microwave detection of interstellar vinyl alcohol, $\mathrm{CH}_{2}$ : $\mathrm{CHOH}$, Astrophys. J. 561 (2001) L207-L210.

[59] I.W.M. Smith, B.R. Rowe, Reaction Kinetics at Very Low Temperatures: Laboratory Studies and Interstellar Chemistry, Acc. Chem. Res. 33 (2000) 261-268.

[60] L. Gavilan, J.L. Lemaire, G. Vidali, Are molecule - covered dust grains efficient catalysts of $\mathrm{H}_{2}$ formation in the cold ISM?, Monthly Notices of the Royal Astronomical Society 424 (2012) 2961-2970.

[61] K. Bain, M.H. Towns, A review of research on the teaching and learning of chemical kinetics, Chem. Educ. Res. Pract. 17 (2016) 246-262.

[62] P.D. Pacey, Changing conceptions of activation energy, J. Chem. Educ. 58 (1981) 612.

[63] S.P. Davis, M.C. Abrams, M.L.P. Rao, J.W. Brault, CN vibrationrotation spectrum, J. Opt. Soc. Am. B. 8 (1991) 198-200.

[64] M.C. McCarthy, S. Mohamed, J.M. Brown, P. Thaddeus, Detection of low-frequency lambda-doublet transitions of the free ${ }^{12} \mathrm{CH}$ and ${ }^{13} \mathrm{CH}$ radicals, Proc. Natl. Acad. Sci. U. S. A. 103 (2006) 12263-12268.

[65] C.H. Townes, Microwave Evidence for Interstellar Molecules, in: C. De Jager (Ed.), Highlights of Astronomy: As presented at the XIVth General Assembly of the I.A.U. 1970, Springer Netherlands, Dordrecht, 1971, pp. 359-365.

[66] V.S. Jackson, D.L. Williams, Particle on a Ring Spectroscopic Selection Rules Determined by Group Theory, J.Chem.Ed. 92 (2015) 2165-2169.

[67] C. Brand, W.L. Meerts, M. Schmitt, How and Why Do Transition Dipole Moment Orientations Depend on Conformer Structure?, J.Phys.Chem.A 115 (2011) 9612-9619.

[68] A.M. Ellis, Spectroscopic Selection Rules: The Role of Photon States, J.Chem.Ed. 76 (1999) 1291.

[69] K.I. Oberg, Photochemistry and Astrochemistry: Photochemical Pathways to Interstellar Complex Organic Molecules, Chem. Rev. 116 (2016) 9631-9663.

[70] T.L. Wilson, W. Batrla, Radio astrochemistry, EAS Publ. Ser. 15 (2005) 331-345.

[71] G. Wlodarczak, Rotational spectroscopy and astrochemistry, J. Mol. Struct. 347 (1995) 131-142.

[72] G.R. Carruthers, Atomic and molecular hydrogen in interstellar space, Space Sci. Rev. 10 (1970) 459-482.

C The Author(s) 2019. This article is an open access article distributed under the terms and conditions of the Creative Commons Attribution (CC BY) license (http://creativecommons.org/licenses/by/4.0/). 